\title{
Vegetable production in Togo and potential impact of pesticide use practices on the environment
}

\author{
Lakpo Koku AGBOYI ${ }^{1,2^{*}}$, Koffi Moïse DJADE ${ }^{3}$, Koffi Mensah AHADJI-DABLA ${ }^{2}$, \\ Guillaume Koffivi $\mathrm{KETOH}^{2}$, Yaovi NUTO ${ }^{2}$ and Isabelle Adolé GLITHO ${ }^{2}$ \\ ${ }^{I}$ UR Défense des Cultures et Biotechnologie Végétale, Institut Togolais de Recherche Agronomique (ITRA), \\ B.P 1163, Lomé, Togo. \\ ${ }^{2}$ Laboratoire d'Entomologie Appliquée, Université de Lomé, 01 B.P 1515 Lomé 01, Togo. \\ ${ }^{3}$ Ecole Supérieure d'Agronomie, Université de Lomé, 01 B.P 1515 Lomé 01, Togo. \\ "Corresponding author; E-mail: agboyikoku@yahoo.fr; BP: 1163, Lomé, Togo; Tel: +228 90288882 , \\ Fax: +22822251559
}

\begin{abstract}
In West Africa, market gardening is considered one of the sectors in agriculture that consumes lots of pesticides. In order to study (i) the principal protection practices of vegetables and (ii) the inherent environmental risks to pesticide use practices, a survey was carried in Togo from 2010 to 2011. A random selection of 161 farmers were interviewed on their farms, which are distributed over the most important vegetable production sites located in dry Savanna, forests and littoral zones of Togo. The results showed that $88 \%$ of farmers interviewed responded that, insects are the most important vegetable pests in Togo. Crop protection practices are primarily based on excessive use of synthetic pesticides which in most cases include organophosphates $(27.3 \%)$ and pyrethroids (18.2\%), known to be dangerous to human health and environment. Despite the excessive use of pesticides, farmers revealed that insect pests continue to cause serious damages, which is an indication that they have developed a resistance to pesticides. Moreover, about $80 \%$ of farmers did not have adequate materials for handling and application of pesticides and are thus exposed to pesticide poisoning. An integrated pest management programme based on crop rotation, biological control and biopesticides is discussed.
\end{abstract}

() 2015 International Formulae Group. All rights reserved.

Keywords: Farmers, market gardening, crop protection, pests' resistance.

\section{INTRODUCTION}

Vegetables are important components of daily diets in Togo, and an important income-generating activity for smallholder farmers in urban centres and rural areas (Kanda et al., 2014). Unfortunately, farmers rely on a lot of inputs in West Africa, particularly pesticides for vegetable production in market gardening (Coulibaly et al., 2008). Several types of agricultural pesticides are being used by farmers in Togo to control several vegetable crop pests. However, farmers' practices in the use of these pesticides are not well known, as well as the impact of these pesticides on the environment. Synthetic pesticides are the most available pesticides on the markets in Togo and consequently, the most accessible to 
farmers who in turn use them inadequately (Mondédji et al., 2014). In spite of the excessive amounts of pesticides used on vegetables, significant crop losses are often reported by farmers, which confirm a reduction of some vegetables pests' sensitivity. In Togo, the diamondback moth, Plutella xylostella L. (Lepidoptera: Plutellidae) can cause more than 50\% of crop losses in cabbage farms treated with various groups of synthetic insecticides (Agboyi et al., 2013).

This study aims at (1) assessing various constraints to vegetable production according to farmers' perceptions, (2) presenting the vegetable protection practices of farmers against pests and diseases and (3) assessing the potential impact of the pesticides use on the environment and their implication in pests' resistance, especially for $P$. xylostella.

\section{MATERIALS AND METHODS Study sites}

The survey was carried out during the period of 2010-2011 and the randomly selected farmers were drawn from the most significant vegetable production sites in three agro-ecological areas of Togo. The highest number of farmers interviewed was from the dry Savanna $(n=101)$ followed by the forests $(n=30)$ and the littoral $(n=30)$. The farmers interviewed were owners of market gardening farms.

\section{Data collection}

A total of one hundred and sixty one (161) farmers were interviewed on farms in various vegetable production sites, using a semi-structured questionnaire composed of 34 questions. Some questions were related to the answers that preceded them. Farmers interviewed were selected randomly on the study sites. The hazard level and the potential impact of pesticides used by vegetables growers were evaluated by using the World Health Organization (WHO) Hazard Class and a model called "Environmental Impact Quotient (EIQ)" respectively. The WHO Hazard Class used was lately established after the revision of the classification criteria in 2009. This new WHO Hazard Class was established in order to harmonize the system of classification and labelling of chemicals. The Globally Harmonized System (GHS) is largely used nowadays for the classification of the pesticides according to their level of danger worldwide (WHO, 2010). The pesticides classification criteria are primarily based on the acute dermal and oral toxicity of the compound; i.e. the dose able to kill $50 \%$ of a large population $\left(\mathrm{LD}_{50}\right)$ of rats (Table 1$)$.

To evaluate the potential impacts of the pesticides identified during our investigations, we used the EIQ model, developed by Kovach et al. (1992) in the Integrated Pest Management (IPM) Program at Cornell University. The EIQ model has important characteristics which make it very adequate for the evaluation of the environmental impacts of agricultural pesticides and even for decision-making with regards to environmental protection (Nissen et al., 2001). It takes into account both the toxicity of the pesticides to farm workers, consumers, as well as an ecological component. The potential EIQ is predetermined for many agricultural pesticides starting from toxicological data obtained from several studies. The toxicity and indices of exposure are scored 1, 3 or 5 according to the importance of potential chronic toxicity, in order to make the parameters of toxicity comparable between them (Gallivan et al., 2001). Thus, the score allotted to the parameters varies according to the pesticides' danger. The EIQ is given starting from the sum of the effects on farm workers, consumers and ecological component, according to the formulas hereafter:

- Effects on farmworkers = Applicator + Picker

$C((D T \times 5)+(D T \times P))$ 
- Effects on consumers = Food residue + Groundwater

$C\left(\frac{S+P}{2}\right) \times S Y+L$

- Effects on ecological component $=$ Fish + Bird + Bee + other Beneficial arthropods

$(F \times R)+\left(D \times \frac{S+P}{2} \times 3\right)+(Z \times P \times 3)+(B \times P \times 5)$

$$
\begin{gathered}
Q I E=\left[C((D T \times 5)+(D T \times P))+\left(\frac{C(S+P)}{2} \times S Y+L\right)\right. \\
\left.+\left((F \times R)+\left(\frac{D(S+P)}{2} \times 3\right)+(Z \times P \times 3)+(B \times P \times 5)\right)\right] / 3
\end{gathered}
$$

With

DT = dermal toxicity, $\mathrm{C}=$ chronic toxicity, $\mathrm{SY}=$ systemicity, $\mathrm{F}=$ fish toxicity, $\mathrm{L}=$ leaching potential, $\mathrm{R}=$ surface loss potential, $\mathrm{D}=$ bird toxicity, $\mathrm{S}=$ soil half-life, $\mathrm{Z}=$ bee toxicity, $\mathrm{B}=$ beneficial arthropod toxicity, $\mathrm{P}=$ plant surface half-life.

In this paper, the potential EIQ of pesticides used on vegetables were obtained from NYS IPM EIQ Database of 2012, developed by the Integrated Pest Management Program at Cornell University.

\section{Data analysis}

Data collected were encoded using Microsoft Excel 2010. The data were then analysed using the software SPSS 16.0 to calculate the proportion of various parameters. The levels of impact (LI) of pesticides were classified in (i) low LI $(0 \leq \mathrm{EIQ} \leq 20)$, (ii) medium LI $(21 \leq \mathrm{EIQ} \leq 40)$ and (iii) High LI (EIQ $\geq 41$ ), adapted from the classification of Mazlan and Mumford (2005).

\section{RESULTS}

\section{Farmers' socio-economic background}

The majority of farmers (92\%) interviewed on the vegetable production sites were men (Table 2). Women owners of market gardening farms were thus very few. The majority of farmers $(63 \%)$ were younger than 41 years old and the maximum age was
50 years. $76 \%$ of farmers were married and $24 \%$ were single. Moreover, the majority of farmers $(71 \%)$ had received a school education and $56 \%$ among them have had a secondary level of education. Therefore, very few farmers (10\%) had received formal training on growing vegetables (Table 2 ).

\section{Crop cultivation systems on the market gardening sites in Togo}

The main crop cultivation systems on the market gardening sites were polycropping $(100 \%)$ and crop rotation (100\%) (Table 3). None of the farmers adopted monoculture practices. The farming system choice was especially influenced by the market. $76 \%$ of farmers chose their cropping system according to the market. A considerable proportion of farmers $(26 \%)$ also used the cropping system as a technique to control pests' resistance, but very few of them $(4 \%)$ used it for improving the fertility of their soil (Table 3).

\section{Species of vegetable crops grown}

The survey revealed that nineteen vegetable species were being cultivated on the market gardening sites under polycropping practice (Table 4). This practice was dominated by some crop species like cabbage (Brassica oleracea, 67\%), lettuce (Lactuca sp., 40\%), pepper (Capsicum spp, 37\%), tomato (Solanum lycopersicum, 35\%) and carrot (Daucus carota, 30\%) (Table 4). The importance of the area occupied by each species was variable. Other crop species such as the French bean (Phaseolus vulgaris, 17\%), gboma (Solanum macrocarpon, 16\%), eggplant (Solanum esculentum, 13\%), onion (Allium cepa, 12\%), beet (Beta vulgaris, 9\%), okra (Abelmoschus esculentus, 7\%), sorrel of Guinea (Hibiscus sabdariffa, 7\%) and cucumber (Cucumis sativus, 6\%) were moderately represented with area varying from extremely to slightly significant (Table 
4). The crop species slightly represented in the market gardens visited were zucchini (Cucurbita pepo, 4\%), amaranth (Amaranthus spp, 3\%), adémè (Amaranthus spp, 2\%), manioc (Manihot esculenta, 2\%), cowpea (Vigna unguiculata, 2\%) and melon (Cucumis melo, 1\%).

Cabbage cultivation: constraints and protection practices of farmers

Insect pests, particularly $P$. xylostella and several Aphis species, represented the major constraint $(67 \%)$ of cabbage cultivation reported by farmers (Table 5). The attack of cabbages by phytopathology agents were evoked by only $6 \%$ of farmers. Other constraints, such as difficulties of access to inputs and water, soil degradation, drop in sales and attacks of molluscs, were revealed by $16 \%$ of farmers. Faced by these constraints, most of the farmers (72\%) adopted the use of synthetic pesticides (Table 5). A considerable proportion of farmers (21\%) used cultural control by adopting crop rotation. Very few farmers $(4 \%)$ used botanical pesticides to control cabbage pests. A proportion of $3 \%$ of farmers used mechanical control against cabbage pests (Table 5).

\section{Pesticides used in market gardening in Togo and targeted pests}

All the farmers $(100 \%)$ have used at least one synthetic pesticide against vegetable pests and there are some who used mixed them (Figure 1 A). A proportion of $45 \%$ of farmers mixed two pesticides to control pests and $22 \%$ used three pesticides. Less than $10 \%$ of farmers mixed 4 or 5 pesticides against their crops pests. Overall, during the surveys, 23 pesticides' active ingredients were identified, based on their labels (Table 6). Among the active ingredients identified, there were $65 \%$ insecticides, $22 \%$ fungicides, $9 \%$ insecticides-nématicides and 4\% insecticideacaricides.

In sum, insects, phytopathology agents, nematodes and molluscs were the categories of pests against which farmers used pesticides (Figure 1 B). However, $88 \%$ of farmers revealed that insect pests were the principal constraints of vegetable cultivation. The problems of diseases caused by phytopathology agents and nematodes were reported by 14 and $12 \%$ of farmers respectively. Damages due to molluscs were reported by only $1 \%$ of farmers interviewed.

Concerning insecticides, $27.3 \%$ of the active ingredients identified belong to the class of organophosphates and $18.2 \%$ to pyrethroids (Table 6). A small proportion of insecticide compounds were classified among organochlorines (9.1\%), neonicotinoids (4.5\%) and Phenylpyrazoles (4.5\%). The class of carbamates was represented by carbofuran, an active ingredient belonging to the type of insecticide-nematicide and accounted for only $4.5 \%$ of common pesticides classes. Another insecticide-nematicide named fenamiphos belongs to organophosphate and accounted also for $4.5 \%$ of pesticides used by farmers. The class of avermectins (4.5\%) was represented by abamectin which is a biopesticide belonging to insecticideacaricide. Only $8 \%$ of farmers used botanical insecticides resulting from ashes of plants, neem seeds or leaves extracts and tobacco leaves extract. However, the number and the amount of active ingredient in these compounds were not evaluated. Therefore, their WHO Hazard Class and EIQ were not indicated. For fungicides, the class of alkylenbis (dithiocarbamate) represented $10 \%$ of the pesticides used (Table 6). Those of Phenylamides (acylamines) and Benzimidazoles accounted for only 5\% each one. 
Generally, the most frequent active ingredients in the pesticides used by farmers were Lambda-cyhalothrin (19\%), Deltamethrin (17\%), Cypermethrin (14\%), Acetamipride (11\%), Abamectin (11\%) and Mancozeb (10\%) (Table 6). The others active ingredients were used by a very few farmers (1-6\%). It is worth mentioning that $41 \%$ of farmers used non identified pesticides and $8 \%$, botanical pesticides respectively.

According to WHO Hazard classification, the majority of pesticides, especially insecticides are highly or moderately hazardous (Table 7). However, some pesticides belong to fungicides such as Maneb, Mancozeb and Thiophanate-methyl are unlikely to present acute hazard. Other insecticides such as Malathion and Endrin were slightly hazardous and obsolete respectively.

Concerning the potential environmental impacts of the pesticides, all the active ingredients used by farmers has an EIQ higher than the threshold of the low level of impact $(E I Q=20)$. Only the fungicide Metalaxyl-M present a potential EIQ lower than 20 .
Personal protective equipment used by farmers during pesticides handling and application

A proportion of $76 \%$ of the market gardeners declared that they have personal protective equipment against pesticides exposure (Figure 2). However, further investigation about the materials necessary to constitute normal protective equipment against pesticides exposure revealed that about $80 \%$ of these farmers did not have latex gloves, rubber boots and long sleeved shirt for pesticides handling and application (Figure 2). Moreover, $73 \%$ of the farmers did not have a respirator and only $51 \%$ had protective eyewear. Nevertheless, a high proportion (73\%) of market gardeners had long pants kept for pesticides handling and application. A small proportion of farmers (32\%) used sprayers (Figure 3). The others who applied the pesticides on their crops with inadequate tools such as watering-cans, brushes and tuft of grass represented $68 \%$ of farmers interviewed.

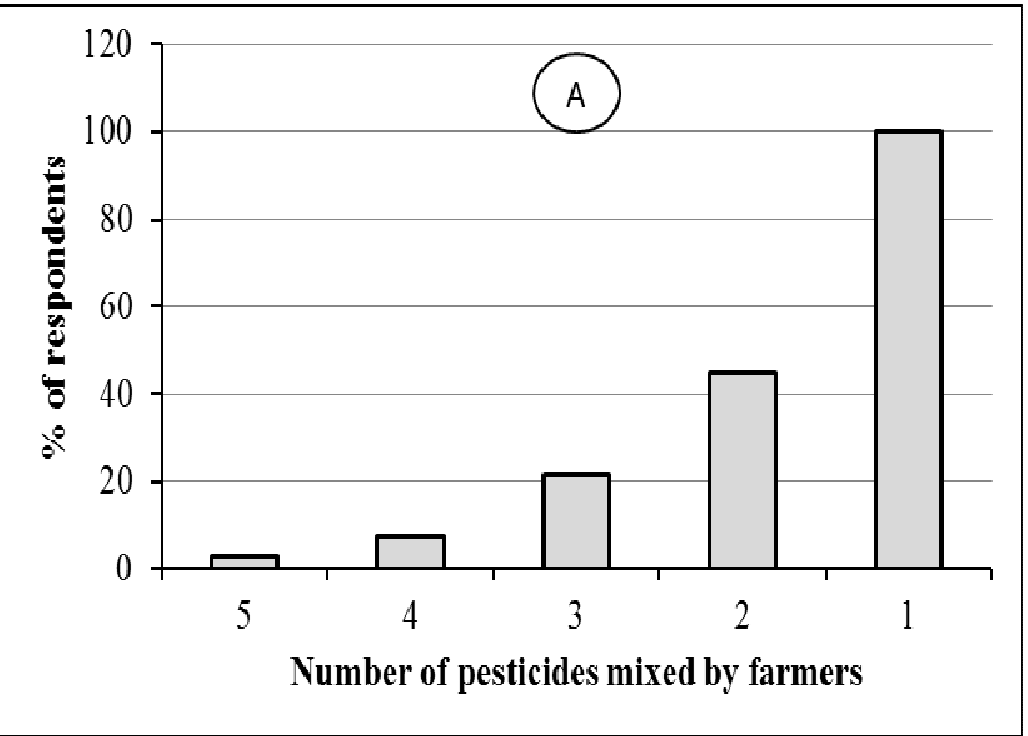




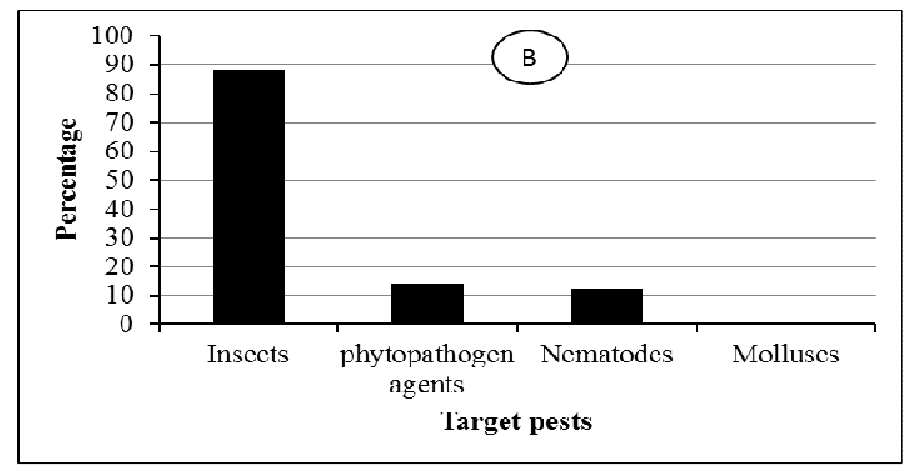

Figure 1: Percentage of farmers using single or mixed pesticides for pests' control in Togo (A) and proportion of target pests (B).

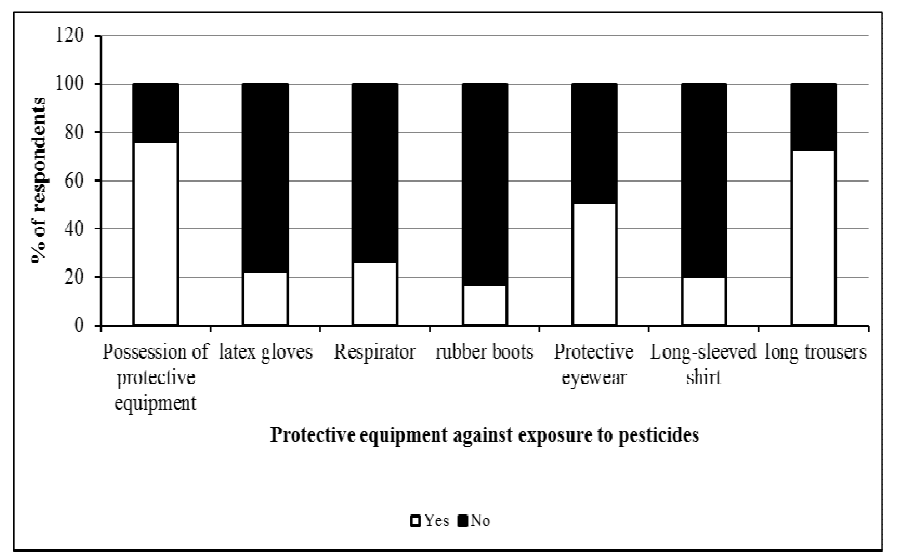

Figure 2: Proportion of farmers having personal protective equipment against exposure to pesticides.

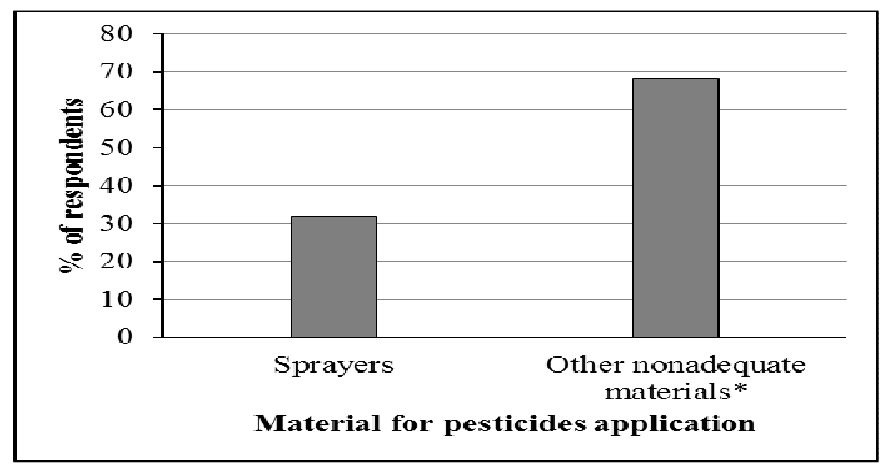

Figure 3: Proportion of farmers using handling and pesticides application materials. * Watering-cans, brushes, tuft of grass. 
Table 1: Pesticides Classification according to WHO Hazard Class 2009.

\begin{tabular}{lccc}
\hline & WHO Class & LD $_{\mathbf{5 0}}$ for the rat $(\mathbf{m g} / \mathbf{k g}$ body weight) \\
\hline & & Oral & Dermal \\
\hline Ia & Extremely hazardous & $<5$ & $<50$ \\
$\mathrm{Ib}$ & Highly hazardous & $5-50$ & $50-200$ \\
$\mathrm{II}$ & Moderately hazardous & $50-2000$ & $200-2000$ \\
$\mathrm{III}$ & Slightly hazardous & Over 2000 & Over 2000 \\
$\mathrm{U}$ & Unlikely to present acute hazard & \multicolumn{2}{c}{5000 or higher } \\
\hline
\end{tabular}

Table 2: Socio-economic background of vegetable farmers interviewed.

\begin{tabular}{lcc}
\hline Farmers' background & & Proportion (\%) \\
\hline Gender & Females & 8 \\
$(\mathrm{n}=161)$ & Males & 92 \\
\hline Age category $^{\mathrm{a}}$ & $20-40$ ans & 63 \\
$(\mathrm{n}=41)$ & $41-50$ ans & 37 \\
\hline & Maried & 76 \\
Matrimonial statut & $\mathrm{a}$ & 24 \\
$(\mathrm{n}=41)$ & Single & 0 \\
& Divorced & 0 \\
\hline & Widower & 12 \\
& Graduate & 56 \\
Education level $^{\mathrm{a}}$ & Secondary education & 3 \\
$(\mathrm{n}=41)$ & Primary education & 7 \\
& Reading and writing taught & 10 \\
& Training in vegetable & 12 \\
\hline
\end{tabular}

n: number of farmers interviewed; a: characteristic of some farmers interviewed in the dry Savanna.

Table 3: Cropping systems used by vegetable growers in Togo.

\begin{tabular}{cc}
\hline Parameters & $\begin{array}{c}\text { Proportion } \\
(\mathbf{\%})\end{array}$ \\
\hline Cropping systems ( $\mathrm{n}=161)$ & 100 \\
Polycropping & 0 \\
Monocultures & 100 \\
Crop rotation & \\
& \\
Reason of the choice $(\mathrm{n}=161)$ & 26 \\
Manage pest resistance & 76 \\
Favourable market & 4 \\
Improve soil fertility & \\
\hline
\end{tabular}


Table 4: Proportion of farmers growing each crop and the importance of crops' area on the farms.

\begin{tabular}{|c|c|c|c|c|c|c|c|}
\hline Crop $^{a}$ & & Propor & of farmers b & $\begin{array}{r}\text { e importanc } \\
(n=\end{array}$ & $\begin{array}{l}\text { ff the area oc } \\
161)\end{array}$ & ipied by the crops or & farm \\
\hline Common name & Scientific name & $\begin{array}{c}\text { Extremely } \\
\text { important } \\
(\%)\end{array}$ & $\begin{array}{c}\text { Very } \\
\text { important } \\
(\%)\end{array}$ & $\begin{array}{c}\text { Important } \\
(\%)\end{array}$ & $\begin{array}{c}\text { Moderately } \\
\text { important } \\
(\%)\end{array}$ & $\begin{array}{c}\text { Slightly important } \\
(\%)\end{array}$ & $\begin{array}{c}\text { Total } \\
\text { proportion }\end{array}$ \\
\hline Amaranth & Amaranthus spp & 0 & 1 & 1 & 1 & 0 & 3 \\
\hline Eggplant & Solanum esculentum & 5 & 3 & 4 & 1 & 0 & 13 \\
\hline Beet & Beta vulgaris & 1 & 4 & 2 & 1 & 1 & 9 \\
\hline Carrot & Daucus carota & 12 & 7 & 9 & 1 & 1 & 30 \\
\hline Cabbage & Brassica oleracea & 33 & 21 & 8 & 3 & 2 & 67 \\
\hline Cocumber & Cucumis sativus & 1 & 2 & 1 & 1 & 1 & 6 \\
\hline Adémè & Corchorus olitorius & 0 & 0 & 1 & 1 & 0 & 2 \\
\hline Zucchini & Cucurbita pepo & 0 & 1 & 2 & 1 & 0 & 4 \\
\hline Gboma & Solanum macrocarpon & 2 & 5 & 3 & 3 & 3 & 16 \\
\hline Okra & Abelmoschus esculentus & 2 & 1 & 2 & 1 & 1 & 7 \\
\hline French bean & Phaseolus vulgaris & 3 & 6 & 4 & 3 & 1 & 17 \\
\hline Lettuce & Lactuca sp. & 8 & 16 & 9 & 6 & 1 & 40 \\
\hline Manioc & Manihot esculenta & 1 & 1 & 0 & 0 & 0 & 2 \\
\hline Melon & Cucumis melo & 1 & 0 & 0 & 0 & 0 & 1 \\
\hline Cowpea & Vigna unguiculata & 0 & 1 & 1 & 0 & 0 & 2 \\
\hline Onion & Allium cepa & 3 & 6 & 2 & 0 & 1 & 12 \\
\hline Sorrel of Guinea & Hibiscus sabdariffa & 1 & 1 & 2 & 2 & 1 & 7 \\
\hline Pepper & Capsicum spp & 9 & 12 & 9 & 6 & 1 & 37 \\
\hline Tomato & Solanum lycopersicum & 17 & 5 & 9 & 2 & 2 & 35 \\
\hline
\end{tabular}

n: number of farmers interviewed; a: The crops in this table were those really present on the market gardening sites at the time of the survey. 
Table 5: Cabbage cultivation constraints and protection practices used by farmers in Togo.

\begin{tabular}{|c|c|}
\hline \multirow{2}{*}{$\begin{array}{l}\text { Parameters } \\
\text { Cabbage cultivation problems }(\mathrm{n}=161)\end{array}$} & \multirow[t]{2}{*}{ Proportion (\%) } \\
\hline & \\
\hline - Damages caused by insect pest ${ }^{\mathrm{a}}$ & 67 \\
\hline - Diseases & 6 \\
\hline - Others $^{\mathrm{b}}$ & 16 \\
\hline \multicolumn{2}{|l|}{ Solutions adopted by farmers $(n=161)$} \\
\hline - Use of synthetic pesticides & 72 \\
\hline - Use of biopesticides ${ }^{c}$ & 4 \\
\hline - Mechanical control & 3 \\
\hline - $\quad$ Cultural control (crop rotation) & 21 \\
\hline
\end{tabular}

Table 6: Pesticides used by famers in Togo and their hazard level and potential impact on the environment.

\begin{tabular}{|c|c|c|c|c|c|c|}
\hline \multicolumn{3}{|c|}{ Pesticide } & \multirow{2}{*}{$\begin{array}{c}\text { Proportion } \\
\text { of farmers } \\
(\%)\end{array}$} & \multirow{2}{*}{$\begin{array}{c}\text { WHO } \\
\text { Hazard } \\
\text { Class }\end{array}$} & \multicolumn{2}{|c|}{$\begin{array}{c}\text { Potential environmental impact } \\
\text { Quotient (EIQ) }\end{array}$} \\
\hline Type & Class & Active ingredient & & & Value of EIQ & $\begin{array}{l}\text { Level of impact } \\
\text { (LI) }\end{array}$ \\
\hline & Organochlorines $(9,1 \%)$ & DDT & 4 & II & - & - \\
\hline & & Endrin & 2 & $\mathrm{O}$ & - & - \\
\hline & & Cypermethrin & 14 & II & 36,35 & Medium $^{c}$ \\
\hline & Pyrethroïds $(18,2 \%)$ & Lambda-cyhalothrin & 19 & II & 44,17 & $\operatorname{High}^{\mathrm{d}}$ \\
\hline & & Deltamethrin & 17 & II & 28,38 & Medium \\
\hline & & Fenpropathrin & 2 & II & 25,33 & Medium \\
\hline & & Dimethoate & 6 & II & 33,49 & Medium \\
\hline & & Profenofos & 1 & II & 59,53 & High \\
\hline \multirow[t]{7}{*}{ Insecticide $(65 \%)$} & Organophosphates $(27,3 \%)$ & Malathion & 1 & III & 23,83 & Medium \\
\hline & & Chlorpyrifos-ethyl & 1 & II & 26,85 & Medium \\
\hline & & Acephate & 1 & II & 24,88 & Medium \\
\hline & & Cadusafos & 1 & $\mathrm{Ib}$ & - & - \\
\hline & Neonicotinoides $(4,5 \%)$ & Acetamiprid & 11 & - & 28,73 & Medium \\
\hline & Phenylpyrazoles $(4,5 \%)$ & Fipronil & 1 & II & 88,25 & High \\
\hline & Botanicals & Insecticides derived from plants $^{\mathrm{a}}$ & 8 & - & - & - \\
\hline
\end{tabular}




\begin{tabular}{|c|c|c|c|c|c|c|}
\hline \multirow{2}{*}{$\begin{array}{c}\text { Insecticide-Nematicide } \\
(9 \%)\end{array}$} & Organophosphates & Fenamiphos & 2 & $\mathrm{Ib}$ & 71,33 & High \\
\hline & $\begin{array}{c}(4,5 \%) \\
\text { Carbamates } \\
(4,5 \%)\end{array}$ & Carbofuran & 4 & $\mathrm{Ib}$ & 50,67 & High \\
\hline \multirow[t]{4}{*}{$\begin{array}{c}\text { Insecticide-Acaricide } \\
(4 \%)\end{array}$} & $\begin{array}{c}\text { Avermectins } \\
(4,5 \%)\end{array}$ & Abamectin & 11 & - & 34,68 & Medium \\
\hline & $\begin{array}{c}\text { Alkylen-bis (dithiocarbamate) } \\
(9,1 \%)\end{array}$ & Maneb & 1 & $\mathrm{U}$ & 21,43 & Medium \\
\hline & & Mancozeb & 10 & $\mathrm{U}$ & 25,72 & Medium \\
\hline & $\begin{array}{c}\text { Phenylamide (acylamine) } \\
(4,5 \%)\end{array}$ & Metalaxyl-M & 1 & II & 19,07 & Low $^{b}$ \\
\hline \multirow[t]{2}{*}{$\begin{array}{l}\text { Fongicides } \\
\quad(22 \%)\end{array}$} & $\begin{array}{c}\text { Phénylamide (acylamine) } \\
(4,5 \%)\end{array}$ & Cuprous oxide & 1 & II & - & - \\
\hline & $\begin{array}{c}\text { Benzimidazoles } \\
(4,5 \%) \\
\end{array}$ & Thiophanate-methyl & 1 & $\mathrm{U}$ & 23,82 & Medium \\
\hline- & - & $\begin{array}{l}\text { non identified active } \\
\text { ingredients }\end{array}$ & 41 & - & - & - \\
\hline
\end{tabular}




\section{DISCUSSION}

The market gardening farms in Togo are mainly owned by men. However, even though men are the main owners, women make a very important contribution in these farms. In fact, not only the tradition in subSaharan Africa, especially in Togo is unfavourable for women's access to agricultural lands but, it does not exclude their participation in the agricultural activities. A study carried out in five areas of Ghana by Duncan (2004) showed that from 1970 to 1984 , the number of women farmers increased by $102 \%$, although they were not the majority owners of farms. This inequality of access to the basic agricultural productive resources particularly lands was also reported by FAO (2011) which estimates that only $15 \%$ women farmers are owners of farm in Sub-Saharan Africa.

Besides, the activities in market gardening farms are often carried out by young people who are mostly married, confirming the crucial contribution of market gardening into social stability. The majority of these young farmers had a secondary level of education and are thus, potentially able to easily adopt new technologies with respect to good agricultural practices. However, very few among them had received training on sustainable cultivation practices of vegetables. Consequently, the non-observance of good plant production practices, especially the inadequate and abusive use of agricultural inputs such as pesticides are frequently observed on farms. Under these conditions, there are risks of environmental pollution related to current farmers' practices. These bad agricultural practices observed in Togo are also reported in other countries of West Africa (Obeng-Ofori and Ankrah, 2002; Avicor et al., 2011).

The predominated cropping systems are crop rotation and polycropping. Some farmers know that they can use them, especially for crop rotation, like preventive measures for crop protection against pests. Indeed, according to James et al. (2010), crop rotation can be used as an effective control technique against pests but, this require good knowledge of farmers on plants' sensitivity to the pests. Obopile et al. (2008) found also in Botswana that crop rotation is the principal farming technique of crops protection adopted by the farmers against vegetable pests in their market garden.

In Togo, according to our results, there is a great diversity of crops grown on the market gardening sites, making it possible to establish beneficial crop rotation systems against pests.

Cabbage, lettuce, pepper, tomato and carrot were the most significant plants species according to the area occupied on the farms and the proportion of farmer who cultivate them throughout the country.

The major constraint of vegetables production revealed by the majority of farmers is the attacks of insect pests. This result is similar to those of the surveys on vegetable production sites carried out by Avicor et al. (2011) in Ghana and Mondédji et al. (2014) in Togo. For cabbage production in particular, in spite of the great dependence of farmers to chemical control, it was revealed that the major pest $P$. xylostella continues to cause serious damage. Indeed, the excessive use of synthetic insecticides on cabbage by farmers, would involve a rapid reduction of the susceptibility of in the targeted insects to the compound used against them, because of the development of resistance mechanisms. It is well known that when a population of insects is continuously exposed to insecticides, its sensitivity to the toxic molecules decreases, because of the selection of resistant individuals (Shono and Scott, 2003). It is the case of $P$. xylostella which is largely known for its great capacity to develop resistance to several classes of insecticides (Tsukahara et al., 2003; Nakasuji et al., 2006). 
The majority of pesticides used by farmers were insecticides, confirming their efforts to fight against insect pests which represent the major constraint of vegetable crops. The insecticides used belong to various classes of which the most significant are organophosphates and synthetic pyrethroids. The class of pyrethroides was also identified in West Africa, precisely in Ghana like the most insecticide class used by farmers (Obeng-Ofori and Ankrah, 2002). Insecticides belonging to the class of organochlorines are still being used on vegetable crops by the farmers, although they are obsolete. These are probably from old and not destroyed stocks which continue to circulate illegally in West African countries.

Moreover, the majority of pesticides used by farmer are highly or moderately hazardous according to the WHO Hazard Class, and their potential EIQ are high or medium. Farmers' crop protection practices based on the intensive use of hazardous pesticides throughout most of vegetable farms in West Africa (PAN UK, 2007; Coulibaly et al., 2008) especially in Togo would constitute a factor worsening not only the farmers and consumers intoxication but also the environmental pollution. This agricultural practice is also at the origin of the qualitative and quantitative modifications of the ecosystems (FAO, 2007), through the pollution of the environment, the elimination of the useful insects and the selection of resistant pests.

The use of incomplete personal protective equipment during pesticides handling and applications and the inadequacy of materials used for spraying pesticides can be considered as the factors which would facilitate famers poisoning in Togo. According to PAN UK (2007), the lack of protective equipment against the pesticides constitutes a serious source of poisoning to farmers in Africa. Williamson (2008) estimated that the indirect cost related to misuse of agricultural pesticides constitutes a great expense supported by rural communities in Africa. According to this author, the expenses are made up by: (i) the health damage of farmers and consumers, (ii) the pesticides resistance development in crop pests, (iii) the negative impacts on beneficial organisms and (iv) the loss of livestock and biodiversity.

\section{Conclusion}

The present study shows that in Togo, the market gardening farms are mostly owned by men. The ignorance of good crop protection practices due to the insufficiency of training for the majority of farmers on vegetable protection, in spite of their good level of education, lead to the excessive use of several pesticides which are very hazardous to human and environmental health. Organophosphates and pyrethroids are the classes of pesticides mostly used by farmers in Togo. The use of inadequate materials for pesticides application, likewise the excessive use of pesticides having various modes of action contribute to the development of the resistance revealed by some pests, especially P. xylostella. The recourse to alternative control methods such as crop rotation, biological control and insecticides of natural origins, in an Integrated Pest Management (IPM) approach would contribute to a better insecticides resistance management and reduce the agricultural impacts on the environment. Therefore, the effectiveness of these alternative methods and their impact on beneficial arthropods is discussed.

\section{ACKNOWLEDGMENTS}

We thank Anna Yuwen and Francis Mwambo both of the Center for Development Research (ZEF) University of Bonn for making valuable comments on the manuscript of this paper. We are also grateful to the farmers for granting us access to their farms 
and for the data collection without which this study would not have been possible.

\section{REFERENCES}

Agboyi KL, Ketoh GK, Martin T, Glitho IA. 2013. Beauveria bassiana 5653 could be an alternative to synthetic insecticides against Plutella xylostella in Togo. In Proceedings of the $1^{\text {st }}$ International Conference on Pesticidal Plants, Ogendo JO, Lukhoba CW, Bett PK Machocho AK (eds.). Danste Agencies: Nairobi; 249253.

Avicor SW, Owusu EO, Eziah VY. 2011. Farmers' perception on insect pests control and insecticide usage pattern in selected areas of Ghana. $N$ Y Sci. J., 4(11): 23-29.

Coulibaly O, Nouhoheflin T, Aitchedji C, Cherry A, Al-hassan R. 2008. External cost of pesticides use in agricultural production in Benin and Ghana. In Pesticides Management in West Africa, Clarendon H, Youdeowei A (eds). QualiType Limited: Accra; 5-13.

Duncan BA. 2004. Women in Agriculture in Ghana ( $2^{\text {nd }}$ edn). Printright: Accra Ghana.

FAO. 2007. The State of Food and Agriculture 2007: Paying Farmers for Environmental Services. FAO Press: Rome.

FAO. 2011. The state of food and agriculture 2010-2011: Women in agriculture: closing the gender gap for development. FAO Press: Rome.

Gallivan GJ, Surgeoner GA, Kovach J. 2001. Pesticide Risk Reduction on Crops in the Province of Ontario. J. Environ. Qual., 30:798-813.

James B, Atcha-Ahowé C, Godonou I, Baimey H, Georgen G, Sikirou R, Toko M. 2010. Integrated Pest Panagement in Vegetable Production: a Guide for Extension Workers in West Africa. International Institute of Tropical
Agriculture (IITA): Ibadan, Nigeria; $120 \mathrm{p}$.

Kanda M, Akpavi S, Wala K, Djaneye Boundjou G, Akpagana K. 2014. Diversité des espèces cultivées et contraintes à la production en agriculture maraîchère au Togo. Int. J. Biol. Chem. Sci., 8(1): 115-127.

Kovach J, Petzoldt J, Degni J, Tette J. 1992. A method to measure the environmental impact of pesticides. NY Food Life Sci. Bull., 139: 1-8.

Mazlan N, Mumford J. 2005. Insecticide use in cabbage pest management in the Cameron Highlands, Malaysia. Crop Prot., 24: 31-39.

Mondédji AD, Nyamador WS, Amévoin K, Abbey GA, Kétoh GK, Glitho IA. 2014. Analyse des caractéristiques sociodémographiques et identification des perceptions des distributeurs de pesticides et des consommateurs sur l'utilisation d'extraits botaniques dans la gestion des insectes ravageurs des cultures maraîchères au Sud du Togo. Bulletin IFAN Ch. A. Diop, Dakar sér. A, 53(2): 135-150.

Nakasuji F, Chen XD, Sanada-Morimura S, Yanagi SI. 2006. Genetic relationships between development of insecticide resistance and reduction of egg size as a negative effect on the fitness of the diamondback moth Plutella xylostella (Lepidoptera: Ypnomeutidae). Appl. Entomol. Zool., 41(3): 479-486.

Nissen TM, Midmore DJ, Keeler AG. 2001. Biophysical and economic tradeoffs of intercropping timber with food crops in the Philippine uplands. Agricult. Sys., 67: 49-69.

Obeng-Ofori D, Ankrah DA. 2002. Effectiveness of aqueous neem extracts for the control of insect pest cabbage (Brassica oleracea var capitata L.) in the Accra plains of Ghana. Agricultural and 
Food Sciences Journal of Ghana, 1: 8394.

Obopile M, Munthali DC, Matilo B. 2008. Farmers' knowledge, perceptions and management of vegetable pests and diseases in Botswana. Crop Prot., 27: 1220-1224.

PAN UK. 2007. Hazardous pesticides and health impacts in Africa. Food \& Fairness Briefing, 6.

Shono T, Scott JG. 2003. Spinosad resistance in the housefly, Musca domestica, is due to a recessive factor on autosome 1 . Pestic. Biochem. Physiol., 75: 1-7.

Tsukahara Y, Sonoda S, Fujiwara Y, Nakasuji F, sumuki HT. 2003. Molecular analysis of the para-sodium channel gene in the pyrethrinoid-resistant diamondback moth, Plutella xylostella (Lepidoptera: Yponomeutidae). Appl. Entomol. Zool., 38: 23-29.

Williamson S. 2008. The hidden costs of pesticide use in Africa. In Pesticides Management in West Africa, Clarendon H, Youdeowei A (eds). QualiType Limited: Accra; 22-29.

WHO. 2010. The WHO Recommended Classification of Pesticides by Hazard and Guidelines to Classification 2009. WHO : Geneva, Switzerland. 